\title{
Comparing Rainfall Use Efficiency Trends with Expert Judgments for Nation-Wide Land Degradation Assessments: The Case of Senegal
}

\author{
Ben. G. J. S. Sonneveld ${ }^{1}$, Zhanguo Bai ${ }^{2}$, Déthié Soumaré Ndiaye ${ }^{3} \&$ Prem. S. Bindraban ${ }^{2}$ \\ ${ }^{1}$ Centre for World Food Studies of the VU University (SOW-VU), Amsterdam, Netherlands \\ ${ }^{2}$ ISRIC-World Soil Information, Wageningen, The Netherlands \\ ${ }^{3}$ Centre de Suivi Ecologique, Dakar, Senegal \\ Correspondence: Ben. G. J. S. Sonneveld, Centre for World Food Studies of the VU University, De Boelelaan \\ 1105, 1081 HV Amsterdam, Netherlands. Tel: 31-20-598-9321/31-20-598-9304. E-mail: \\ b.g.j.s.sonneveld@vu.nl
}

Received: June 1, 2012 Accepted: July 12, 2012 Online Published: July 26, 2012

doi:10.5539/jsd.v5n8p116

URL: http://dx.doi.org/10.5539/jsd.v5n8p116

\begin{abstract}
This study compares the results of two nationwide land degradation assessments for Senegal. The first approach is based on expert judgments, the second on trend analyses of Rainfall Use Efficiency (RUE). The comparison yields some interpretable results for extreme negative RUE slope values with maximum degrees of land degradation as indicated by experts, yet, overall, the correlation between both approaches proves to be low and without clear sign. As RUE trend analysis suffers from several inherent methodological problems and expert judgments are found to be consistent we consider expert opinions as the preferable option for a nation-wide land degradation assessment in Senegal. Yet, we argue that methodological improvements would increase the explanatory power of the expert approach and consolidate its position in a policy making framework.
\end{abstract}

Keywords: land degradation assessment, rainfall use efficiency, expert judgments, Senegal

\section{Introduction}

Land degradation seriously impairs food security, biodiversity and economic development, especially in lower income countries where land users are highly dependent on the quality of natural endowments (e.g. Lal, 2011). Moreover, capital constraints restrict land users' access to expensive inputs, like fertilizer, that could compensate the deteriorative effects of land degradation (Requier-Desjardins et al., 2011). When land is degraded, its productivity is reduced and many other ecosystem services are deleteriously affected (FAO, 2011). A rural household survey in Senegal showed that the impact of land degradation affected the 'net income situation of the household' (36 percent), 'the productivity of the land' (24 percent) and exacerbated the households' food security (10 percent) (Sonneveld et al., 2011). It is, therefore, critical that techniques are being developed that provide accurate assessments of land degradation that can serve as an early warning system and timely inform decision makers. Moreover, to prioritize interventions such analysis should take place at the national scale, the level where most important decisions concerning land use are taken. However, this is not an easy task. Land degradation is dependent on a complexity of biophysical and socio-economic factors that largely vary in space and time. Moreover, the few countries that avail of a monitoring network that covers interaction between land use and natural resources in sufficient detail can only generate reliable land degradation assessments for small agricultural areas and have to abstain from assessments at national level.

The scientific community addressed these concerns by concentrating, in the last few decades, on the development of land degradation models that were based on physical laws and aimed to be universally applicable. Yet, high expectations in the 1970s of accommodating increasing complexity in these process based models were tempered in the 1990s (Pla Sentis, 1997) as models appeared to be very data demanding (e.g. Mitas \& Mitasova, 1998), vary considerably in their predictive power (e.g. Zeleke, 2000; Yu et al., 2001) and still require a stage of validation. Beven (1999) also found that parameter identification fails and different sets gave equally acceptable fits to observed data, but for entirely different reasons, implying that land degradation models have a limited scope as policy tools. Use of empirical models is also restricted because they lack a rigorous grounding on theory and have to rely on statistically significant relationships that are derived from a particular 
data set (Mitasova et al., 1997). Therefore, these empirical models cannot be extrapolated beyond their data domain with confidence, either to more extreme events or to other geographical areas (Wischmeier, 1976).

The limitations of applying process-based or empirical models at larger scales led to the development of two alternative approaches for nation-wide land degradation assessments. One is based on expert interventions, a second line uses satellite based information on rainfall use efficiency (RUE). The first approach uses expert opinions to make qualitative assessments on the status of land degradation. A well known example is the Global Assessment of Soil Degradation (GLASOD) (Oldeman et al., 1991), where experts gave ordered qualitative judgments on degree and extent of land degradation. Other examples of expert interventions are found in the experience-based scoring systems for biophysical factors and land use (e.g. Liu et al., 2003; Jager, 1994), qualitative assessments (e.g. Gachene, 1995; Desmet et al., 1995) or a combination of erosion models with expert knowledge (e.g. Symeonakis \& Drake, 2004; Hill et al., 2006). Expert based land degradation assessments have in common that they capitalize on spatial analytical tools and display capabilities of GIS to analyze spatial patterns (Aitkenhead \& Aalders, 2011) and identify vulnerable areas. As such, these maps are informative, however, inappropriate for modelling purposes. Moreover, expert judgments are much disputed as they are not tested for their consistency (Niemeijer \& Mazzucato, 2002; Rey et al., 1998), that is, it is not known if different experts would assign the same qualification to sites with similar degree of degradation. Of course, different assessments for similar sites can be caused by differences in perception of the experts or unobserved heterogeneity in the landscape, yet, the tendency should make it clear that assessments converge to a common significance in order to make the results interpretable. Finally, we note that the quantitative interpretation of qualitative expert judgments is inherently unidentifiable. In the last decade there has been a growing interest in a second approach to detect land degradation patterns nation-wide, viz. the application of RUE trend analysis (Geerken \& Ilaiwi, 2004; Prince et al., 1998; Reynolds \& Smith, 2002; Hall et al., 2006; McNaughton et al., 1989; UN, 1994; Fensholt \& Rasmussen, 2011). The RUE is the ratio of Net Primary Production (NPP) over Rainfall, separating vegetation changes caused by fluctuations in rainfall from other factors. RUE trends are estimated according to a linear relationship with years as independent variable. The common interpretation is that negative slopes that are statistically significant indicate land degradation. The Global Assessment of Land Degradation and Improvement exercise within the GEF-UNEP-FAO funded Land Degradation Assessment (LADA) project employed a RUE to adjust the impact of rainfall on trends in NDVI (Bai et al., 2008) for globe and LADA pilot countries (Argentina, China, Cuba, Senegal, South Africa and Tunisia). However, the RUE approach suffered from several methodological complications which we further detail in the section data and methods. Therefore, the LADA project also adopted expert judgments approaches for a nation-wide land degradation assessment in the six pilot countries.

We report in this study on the LADA results of the expert approach and the RUE analysis for Senegal. Before we turn to the specific contributions of this study we give a brief profile of land degradation in Senegal.

\subsection{Land Degradation in Senegal}

A recent article in Nature (Mulitza et al., 2010) showed that sharp increases in dust deposition of terrigenous sediments could be related to vast land degradation processes in Senegal that started in the 1840s. In that period, the ruling French colonial power, promoted cultivation of groundnut as a driver of prosperity and economic growth. Price policies in the last century further endorsed the profitable cultivation of groundnuts, yet, its incessant demand for land started to take a toll on the environment. Land degradation became particularly manifest when the last vestiges of the original wooded savannas and open woodlands were cleared in the $20^{\text {th }}$ century. What remained were agricultural parklands dominated by only few acacias species (Tschakert \& Tappan, 2004) that no longer could protect the soils against wind and water erosion and resulted in less favourable physical and chemical properties in the top soil (Kairé, 2003). During the first half of the $20^{\text {th }}$ century, the expansion of groundnut was further facilitated by construction of roads, railroads and the establishment of a network of processing centres.

From the year of independence, 1960, until 1980, groundnut cultivation was developed by state dominated cooperatives that were encouraged by price protection policies of the French state, its largest importer. The period 1971-1980 suffered from several crises like droughts, price inflation, rapid demographic growth and impoverishment of the rural population. These interrelated factors resulted in more intensive forms of agriculture and the need for fertile land started to exceed its availability (Mortimore et al., 2005); Senegal experienced its first large rural-urban migration (Dianka, 2007).

Reform policies imposed by IMF and World Bank in the 1980's and implemented as the Structural Adjustment Program (SAP), reduced the state involvement but had detrimental effects on management of soil fertility. Under 
SAP, peanut producers were granted higher prices but fertilizer subsidies were abolished. As a result peanut farmers did forego the purchase of chemical amendments (Speirs \& Olson, 1992) and adopted inappropriate production techniques, like sowing at higher densities, to compensate for production losses of individual plants (Kelly et al., 1996). Yet, these short-run payoff strategies (Reardon et al., 1997) only caused a further depletion of the soil resources, trapping farmers into a vicious circle (Reardon et al., 1998).

The causes and impacts of land degradation in Senegal are diverse, which is confirmed by local studies. Wood et al. (2004) found that agricultural extensification in Velingara, a tropical dry woodland area in south-central Senegal, poses a significant threat to both upland woodlands and riparian forests. Furthermore, lack of clarity about the land tenure and land allocation powers of administrative units led to increased clearing of forests and other unsuitable land management techniques (Wood, 2002). Li et al. (2004) showed that total carbon stock in vegetation and soils was reduced significantly due to forest clearing in south-central Senegal. Diouf and Lambin (2001) and Vincke et al. (2009) concluded that the degree of land degradation in Ferlo, North Senegal caused by drought, was dependent on soil quality and anthropogenic pressure. Mbow et al. (2008) found that rapid environmental degradation in Saloum, Central East Senegal was caused by conversion of forest and savannah areas to agricultural land for groundnut cultivation.

We conclude that the historical overview and the various case studies are informative but their findings cannot easily be extrapolated to higher levels and the urgency for the appropriate techniques for a nationwide land degradation assessment remains pending.

\subsection{Contribution of This Study}

Therefore, under the LADA initiative, two studies were organized that made a nationwide inventory of the land degradation problems in Senegal. One study was based on the expert approach using the WOCAT (World Overview of Conservation Approaches and Technologies) methodology (Liniger et al., 2008). For our exercise we selected in each of the 45 departments (second administrative level) a group of local agricultural extension officers with more than 5 years professional experience. Extension workers did avail of a considerable knowledge on the status of land quality in their working regions. In addition, the group was extended with NGO members that were active at the local level and had a long time experience in the field of land resources management. The expert assessments were organized using the WOCAT approach that describes the extent, degree, rate, and other characteristics of land degradation and land conservation technologies. Except for area extent of degraded land, the expert assessments are given in qualitative terms. A second study derived a nationwide inventory on land degradation in Senegal from Bai and Dent (2007), using estimated RUE trends from a linear equation with years as independent variable. These RUE trends were estimated for 3110 grids with a resolution of $8 \times 8 \mathrm{~km}$, thereby covering the entire Senegalese land area. The experts did not have any information of the RUE results and their assessments were only influenced by their own knowledge and experience of land degradation processes.

In this study we aim to compare the results of these two land degradation assessments. We will analyze possible anomalies between expert assessments and RUE analysis, specifically, we evaluate whether information from both sources agrees or disagrees for area share, degree and rate of land degradation. Our map unit of analysis is defined by a crossing of the production systems map and the district map (Figure 1 and Figure 2, respectively). For each map unit experts indicated area share of affected land and the degree and rate of land degradation. Area shares of degraded land for the RUE trend analysis are defined by the share of pixels with a negative slope parameter at a certain confidence level that belonged to that specific map unit. The average of slope values of RUE trend analysis for each map unit that are statistically significant are used to compare the expert judgments for a) degree of land degradation and b) rate, or speed, of land degradation. 


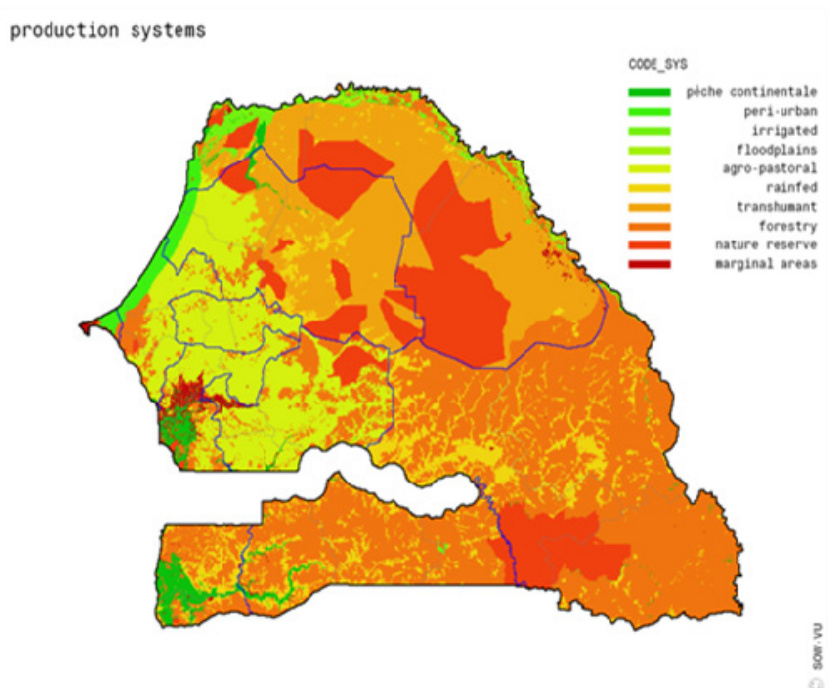

Figure 1. Production system zones in Senegal

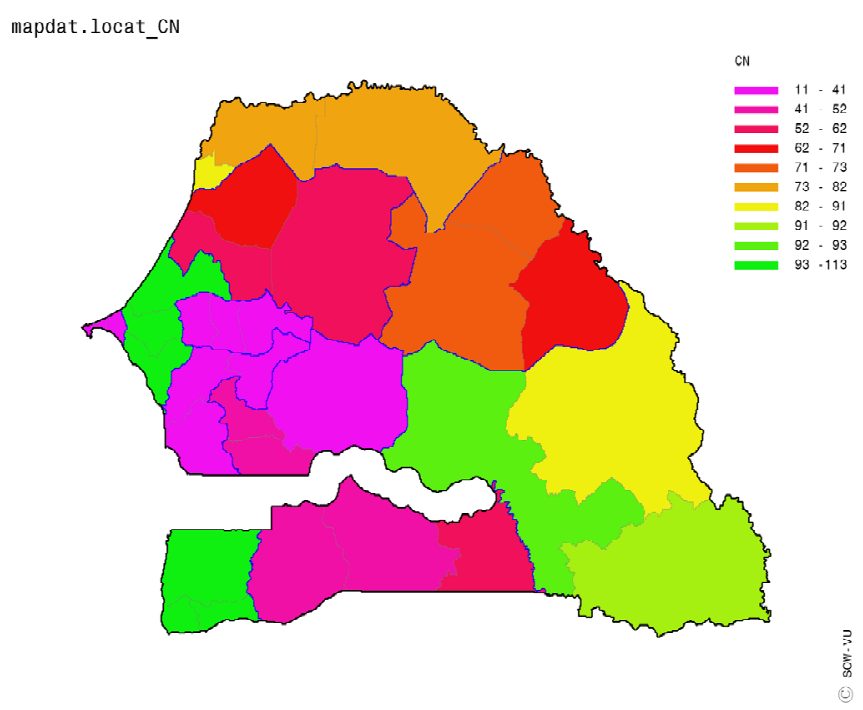

Figure 2. Districts of Senegal

Prior to our actual analysis we address the concerns on the use of qualitative expert judgments to assess the degree of land degradation. We, therefore, test if experts are consistent in their decisions so as to assure that they are a reliable source of information for our comparison. Consistency is tested by comparing expert judgments on degree of land degradation for similar combinations of biophysical conditions and land use, assuming that these sites have the same degree of land degradation. A higher joint occurrence of similar qualitative judgments for the same areas should give confidence that expert judgments are coherent and can be used for further analysis. With reference to the quantitative interpretation of qualitative judgments, data paucity on quantitative land degradation assessments impeded a full empirical analysis in this study, yet, we will address this issue in the conclusion (Section 4).

Concerning the use or RUE data for a comparison with expert judgments, we like to note that conceptually this is cumbersome as the results of the RUE trend analysis are based on regression results which by themselves depend on a number of, possibly untested, assumptions. Therefore, formal statistical analysis that compares the relation between RUE outcomes and expert observations may only lead to results that are difficult to interpret. Yet, as RUE trend analysis is widely used as an indicator of land degradation, we will ignore its history of construction and take the outcomes simply as given to compare them with expert assessments, only using intuitive graphical tools to illustrate the comparison. 
The presentation of this research is organized as follows. Section 2 summarizes data and methodology. Section 3 reports on consistency of expert judgments (3.1) and compares expert judgments and RUE results for assessments of area shares of affected land (3.2), degree of land degradation (3.3) and rates of land degradation (3.4). Section 4 concludes.

\section{Data and Approach}

\subsection{Expert Judgments}

Under the LADA project land degradation assessments of expert judgments identified, for prevailing production systems in the 33 Senegalese districts, one or more area shares with various types of land degradation. For each land degradation type, or a combination thereof, a degree and rate of land degradation were estimated, reflecting, respectively, the intensity and (increasing or decreasing) trends of the degradation process. Extent of affected land is expressed as a share of the production system zone in the corresponding district; degree and rate of land degradation are expressed in ordered qualitative classes (Table 1). In total a 106 expert assessments were made.

Table 1. Numeric codes and description for degree and rate of land degradation*

\begin{tabular}{llll}
\hline Degree of land degradation & & Rate of land degradation & \\
\hline Numeric code & Description & Numeric code & Description \\
\hline 1 & Light & -2 & Moderately decrease \\
2 & Moderate & -1 & Slowly decrease \\
3 & Strong & 0 & No Change \\
4 & Extreme & 1 & Slowly increase \\
& & 2 & Moderate increase \\
& & 3 & Rapid increase \\
\hline
\end{tabular}

*Expert judgments collected under the FAO coordinated LADA project. Source: Sonneveld et al. (2010).

Land degradation assessments were organized in Excel files, one for each district, using single spreadsheets for the prevailing production systems. Areas indicated as 'Marginal' in the production systems map were not included in the assessment.

\subsection{RUE Data}

Data from the RUE analysis and the results are presented in Bai and Dent (2007). The RUE is the ratio of the annual sum of the NPP to the annual rainfall. NPP are calculated from the Normalized Difference Vegetation Index (NDVI) using a linear transformation. NDVI data were obtained from the GIMMS radiometer (AVHRR) data at a resolution of 8-km grids, collected by the National Oceanic and Atmospheric Administration satellites. NDVI data are available for the period 1981 to 2003 and were tested for their NDVI temporal and spatial independence (Tucker et al., 2004). Rainfall data were obtained from Beck et al. (2005) and resampled from $0.5^{\circ}$ lat/lon grids to the NDVI resolution. Yet, RUE trend analysis counts with several methodological problems. First, the fundamental postulation that there is a linear correlation with zero intercept between rainfall and NPP (Houérou, 1984) seems hardly applicable outside arid and semi-arid areas as forest and perennials are less responsive to rainfall as compared to annual vegetation (Huenneke et al., 2002). Second, low correlation between NDVI time series and NPP introduces considerable uncertainty (Bai \& Dent, 2007) in interpretation of RUE data (Wessels, 2009). Third, independently studies of Veron et al. (2006), Safriel (2007) and Bai et al. (2011) reported large variations in RUE response that could not be explained by land degradation, signifying that other factors affected the efficiency of soil moisture for primary productivity. Fourth, Evans and Geerken (2004) found that RUE and rainfall were closely related, which impedes a correct interpretation of RUE trends which are seemingly driven by rainfall rather than land degradation. Fifth, yearly RUE values mask intra-annual variations where vulnerable periods for land degradation during the year are not clearly reflected (Boer \& Puigdefabregas, 2003).

Some of the shortcomings in RUE analysis are being addressed in a research project at the International Soil Reference and Information Centre (ISRIC). The approach is to use a water balance that stores rainfall surplus of previous periods so as to improve the dynamics of water availability and cushion effects of abrupt changes in precipitation patterns (Bindraban et al., 2000; Bindraban et al., 1999). 


\subsection{Trend Analysis}

Trends were determined by linear regression using the equation,

$$
y=\alpha x+\beta
$$

where $x$ stands for the number of the year starting from 1 (1982) to 22 (2003), with $\alpha$ and $\beta$ as parameters to be estimated using OLS. The pixel values of the estimated slope parameter at a certain level of significance are used to compare area extent, degree and rate of land degradation.

\subsection{Visualization Techniques}

The study uses two techniques to visualize the relationship between expert opinions and RUE analysis. The first is the well known scatter plot, indicating the point observations of expert opinions and the RUE analysis. Yet, as it is difficult to visualize patterns from scatter plots we introduce a smoothing technique, based on kernel density regression that interpolate point observations and might reveal prevalent patterns (e.g. Bierens, 1987). The calculations of the kernel are implemented in the Mollifier program (Keyzer \& Sonneveld, 1998) and generate statistical measures of fit at every point, rather than for the full sample only. The Mollifier program offers visual displays of the non-parametric estimates in 3-D graphs while using color shifts in the regression curve and ground plane to depict associated statistics representing, say, reliable areas in the data domains, quality of fit, and covariates.

\subsection{Sequence of Analysis}

The study starts with a test on the consistency of expert opinions. It compares the expert judgments that were given for sites with similar characteristics and land use. Next, we use the results of RUE trend analysis and expert assessment to compare:

a) the shares of affected land

b) degree of land degradation

c) rate of land degradation

\section{Results}

Section 3.1 presents the results on the consistency test of the experts. Next, we make comparisons between the expert assessments and results of the RUE trend analysis for shares of affected land (3.2) and the degree (3.3) and rates of land degradation (3.4).

\subsection{Consistency of Expert Judgments}

The consistency of expert judgments was checked by a cross-comparison of mapping units with identical characteristics. These mapping units were identified by crossing production system zones with GIS layers of rainfall, soil suitability, slope, population density and livestock density. To assist direct comparison we prepared the following maps:

a) Annual rainfall data are presented in three classes: 200-400, 400-700 and $>700 \mathrm{~mm}$.

b) Soil suitability data are given for four classes: unsuitable, moderately suitable, suitable and very suitable.

c) The slope map has five classes: no constraints, slight, moderate, moderate/severe and severe.

d) Livestock density data was categorized as: 0-11, 11-32 and > 32 Tropical Livestock Unit (TLU, Note 1) per sq. km. The lowest threshold is derived from studies on nomadic livestock (e.g. Sonneveld et al., 2010; McDowell \& DeHaan, 1986; Leeuw \& Milligam, 1984) and corresponds to the average TLU density of the transhumant zone in Senegal. The 32 threshold is based on the average value of TLU density in other areas than the transhumant zone.

e) Population data are subdivided into classes ranging from; 0-600, 600-9000 and $>9000$ persons per sq km; the latter category is considered urban population (Note 2) and was excluded.

The combination of maps a-e resulted in homogeneous map units that were linked to expert judgments on the degree of land degradation as indicated in Table 1. Because expert assessments were given for prevailing production systems in each district, only homogeneous map units that occupy more than 20 percent of the production system zones were considered for comparison. Table 2 summarizes the results. In total, 367 sites were identified with more than one counterpart with identical characteristics, varying from 2 identical sites (11 times) to a total of 23 identical sites. This allowed us to make in total 62 comparisons. 
Of these 62 comparisons we found 31 sets of comparable sites where all experts gave identical land degradation assessments. For the remaining 31 sets expert judgments were inconsistent: 17 sets had one class difference and 14 sets two class differences. Yet, in 27 of the 31 sets with inconsistent judgments more than 50 percent of identical assessments were reported. This was less than 50 percent for the other 4 cases.

Table 2. Results of the comparison of expert judgments for identical sites, reporting on a) frequency of occurrence, b) difference in class s estimates and c) maximum percentage of equal assessments. Groups of sets are identified by differences in class estimates and maximum percentage of equal scores for each number of identical sites

\begin{tabular}{|c|c|c|c|c|c|c|c|c|c|c|c|c|c|}
\hline \multirow[b]{2}{*}{$\begin{array}{c}\text { No. of } \\
\text { identical } \\
\text { sites }\end{array}$} & \multirow[b]{2}{*}{$\begin{array}{c}\text { Freq. } \\
\text { identical } \\
\text { sites }\end{array}$} & \multicolumn{3}{|c|}{ First Group } & \multicolumn{3}{|c|}{ Second group } & \multicolumn{3}{|c|}{ Third Group } & \multicolumn{3}{|c|}{ Fourth Group } \\
\hline & & Freq. & $\begin{array}{l}\text { Difference } \\
\text { class } \\
\text { estimates }\end{array}$ & $\begin{array}{c}\text { Max \% } \\
\text { equal } \\
\text { scores }\end{array}$ & Freq. & $\begin{array}{l}\text { Difference } \\
\text { class } \\
\text { estimates }\end{array}$ & $\begin{array}{c}\text { Max \% } \\
\text { equal } \\
\text { scores }\end{array}$ & Freq. & $\begin{array}{l}\text { Difference } \\
\text { class } \\
\text { estimates }\end{array}$ & $\begin{array}{c}\text { Max \% } \\
\text { equal } \\
\text { scores }\end{array}$ & Freq. & $\begin{array}{l}\text { Difference } \\
\text { class } \\
\text { estimates }\end{array}$ & $\begin{array}{c}\text { Max \% } \\
\text { equal } \\
\text { scores }\end{array}$ \\
\hline 2 & 13 & 11 & 0 & 100 & 2 & 1 & 0 & . & . & . & & & \\
\hline 3 & 16 & 15 & 0 & 100 & 1 & 1 & 67 & . & . & . & & & \\
\hline 4 & 5 & 2 & 0 & 100 & 4 & 2 & 50 & & & & & & \\
\hline 5 & 3 & 3 & 1 & 60 & & & & & & & & & \\
\hline 6 & 5 & 1 & 0 & 100 & 2 & 1 & 50 & 2 & 2 & 33 & & & \\
\hline 7 & 5 & 2 & 0 & 100 & 1 & 2 & 71 & 1 & 1 & 57 & 1 & 2 & 57 \\
\hline 8 & 4 & 1 & 2 & 87.5 & 1 & 1 & 75 & 1 & 1 & 62.5 & 1 & 2 & 37.5 \\
\hline 9 & 2 & 1 & 2 & 67 & 1 & 1 & 56 & & & & & & \\
\hline 10 & 1 & 1 & 1 & 60 & & & & & & & & & \\
\hline 11 & 1 & 1 & 1 & 55 & & & & & & & & & \\
\hline 12 & 1 & 1 & 2 & 58 & & & & & & & & & \\
\hline 13 & 1 & 1 & 2 & 61 & & & & & & & & & \\
\hline 14 & 1 & 1 & 2 & 50 & & & & & & & & & \\
\hline 16 & 1 & 1 & 1 & 56 & & & & & & & & & \\
\hline 22 & 2 & 1 & 2 & 86 & 1 & 1 & 72 & & & & & & \\
\hline 23 & 1 & 1 & 1 & 95 & & & & & & & & & \\
\hline
\end{tabular}

In detail:

- Of the 13 sets having 2 sites with similar conditions, 11 reported the same classification for both sites. In the remaining 2 sets there was one class difference;

- 16 sets have 3 sites with similar conditions, for 15 sets judgments were identical and 1 set reported 1 class difference;

- $\quad 5$ sets with 4 sites with similar characteristics were found, 2 of which had the same classification for all 4 sites, 1 set had 3 similar classifications and 5 sets had 2 matching assessments for the 4 sites; both non-matching assessments differed by more than one class;

- $\quad 3$ sets with 5 identical sites gave, in all 3 cases, 3 and 2 identical expert assessments, with one class difference;

- for the 5 sets with 6 sites with similar conditions we found 1 set where all experts gave the same assessment; 2 sets where twice 3 identical scores were given with one class difference and 2 sets where three times 2 similar expert judgments were given with more than one class difference;

- for two sets of 7 sites with similar conditions the same assessment was given; one set reported 71 percent of identical assessments and for 2 sets a 57 percent of the sites were given the same classification with one set 1 class difference and for the other set 2 classes difference;

- $\quad$ One set of 8 sites with similar conditions, had 7 similar scores with 2 classes difference, one set with 6 identical scores and 1 class difference, one set with 62 percent identical scores and 1 class difference and 1 set reported 28 percent identical expert judgments with 2 classes difference;

- $\quad$ There were 2 sets with 9 sites with similar conditions; one set reported 67 percent identical expert judgments with two classes difference; the other set had 57 percent identical judgments with one class difference; 
- There was one set for $10,11,12,13,14$, and 16 sites with similar conditions, with maximum equal scores that varied between 50 and 60 percent with 1 (3 times) or 2 (3 times) classes difference;

- Two sets with 22 sites with similar conditions had high scores of 86 percent equal scores with at most two classes difference and 72 percent equal scores with one class difference;

- $\quad$ Finally, there was one set with 23 sites with similar conditions where we found a remarkable 95 percent of equal scores and one class difference.

Our findings indicate that experts have a reasonable to high consistency in their judgment on the degree of land degradation. In total a 269 , or 73 percent, of identical assessments were given to sites with similar conditions. This is a remarkable result compared to earlier studies (e.g. Sonneveld \& Dent, 2007; Sonneveld, 2003; Sonneveld \& Albersen, 1999) where overall consistency of experts was moderate and cases with deviating assessments prevailed significantly over the few cases with identical scores. Yet, in the earlier mentioned studies individuals were asked about their opinion about land degradation while the WOCAT approach discusses these individual assessments in group sessions. This most likely harmonizes perceptions on land degradation and results in better consistency scores.

\subsection{Comparing Share of Degraded Land}

Using the expert judgments we found for Senegal a 6571990 ha, or 34 percent of the total area (Note 3), affected by land degradation. The bar chart in Figure 3 shows the distribution of area shares as a percentage of total area by degree of land degradation. Less than 5 percent of the land is lightly degraded. Approximately 23 percent is moderately affected, 7 percent strongly, and less than one percent is extremely affected by land degradation. Table 3 summarizes the extent of land degradation and area share by production system.

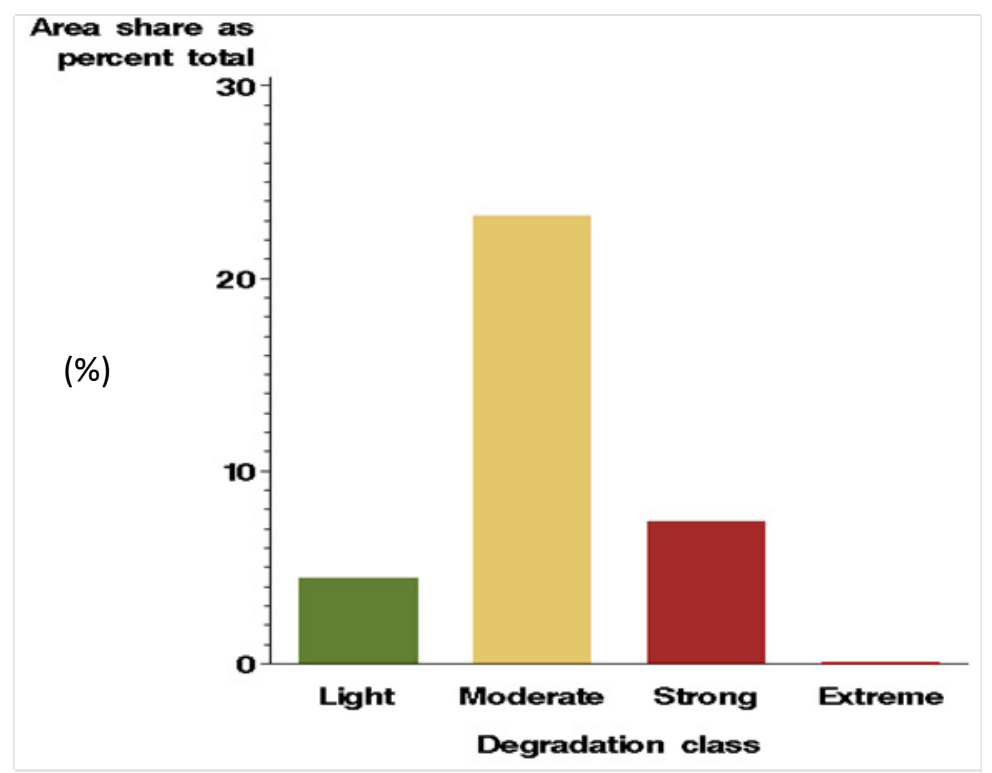

Figure 3. Degree of land degradation; national level

Most affected areas are classified as a 'Moderate', whereby 68 percent of the 'Irrigated' areas stands out as the highest. 'Floodplains', 'Rainfed' and 'Nature reserves' also show high area shares with 'Strong' degradation. 'Peri-urban' and 'Floodplain' cultivation reported areas shares of, respectively, 7 and 1 percent that are extremely degraded (see for further details Sonneveld et al., 2010). 
Table 3. Extent and area share of land degradation by production system

\begin{tabular}{lll}
\hline Production system & Area in ha & Area share production system (\%) \\
\hline Peri-urban & 166703 & 68 \\
Irrigated & 146356 & 73 \\
Floodplains & 73644 & 46 \\
Agro-pastoral & 1380476 & 54 \\
Rainfed & 921637 & 49 \\
Transhumant & 1469989 & 44 \\
Forestry & 1644110 & 21 \\
Nature reserve & 769072 & 26 \\
\hline
\end{tabular}

Source: Sonneveld et al. (2010).

The share of degraded land in the RUE-analysis is, however, dependent on the selection of the confidence interval of the estimated slope parameter. Table 4 illustrates the implications by presenting share of degraded land at national level against different confidence intervals derived from students' $t$-test statistic. The area share of affected land increases, as expected, with lower confidence intervals. At a commonly used threshold of 95 percent confidence interval we see that none of the estimated parameters was significant. Even for the more relaxed condition of 90 percent confidence the affected area is only approximately one third of the expert assessments. The affected area share according to the expert judgment (34 percent) lies between the 90 and 75 percent confidence interval. We, therefore, decided to use these two confidence intervals to compare the estimates on the share of affected land by the experts and the RUE analysis.

Table 4. Share of affected land at national level for different confidence intervals based on t-scores of the slope parameter in the RUE trend equation

\begin{tabular}{cc}
\hline Students t_statistic (confidence interval \%) & share of affected land $(\%)$ \\
\hline$<-0.256 \quad(>60)$ & 67 \\
$<-0.658(>75)$ & 48 \\
$<-1.319 \quad(>90)$ & 13 \\
$<-2.09 \quad(>95)$ & 0
\end{tabular}

Source: Sonneveld et al. (2010).

Figures 4 and 5 compare for each production zone by district the affected area share identified by experts and RUE trend analysis for pixels with a negative slope parameters at, respectively, 90 and 75 percent confidence level.

The effect of the t-test criteria evidently affects the outcome. Figure 4 suggests that experts estimate higher shares of degraded areas as compared to RUE trends while, conversely, Figure 5 shows the tendency that experts give a lower share of degraded areas compared to the RUE trends. Yet, both scatter plots show that a clear correlation is absent and the relationship between area shares indicated by experts and RUE trend analysis is rather diffuse. 


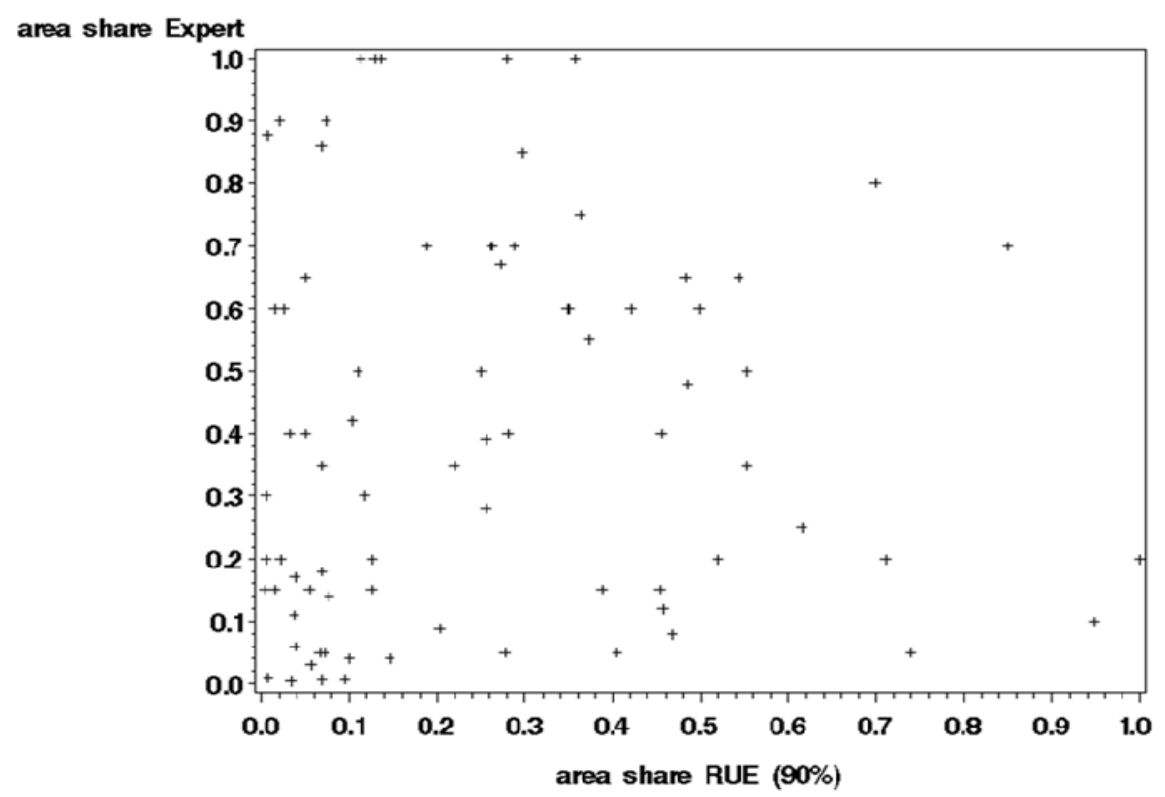

Figure 4. Area shares [0-1] of degraded land by production system zone for RUE trends with slope parameters at 90 percent confidence level and expert assessment

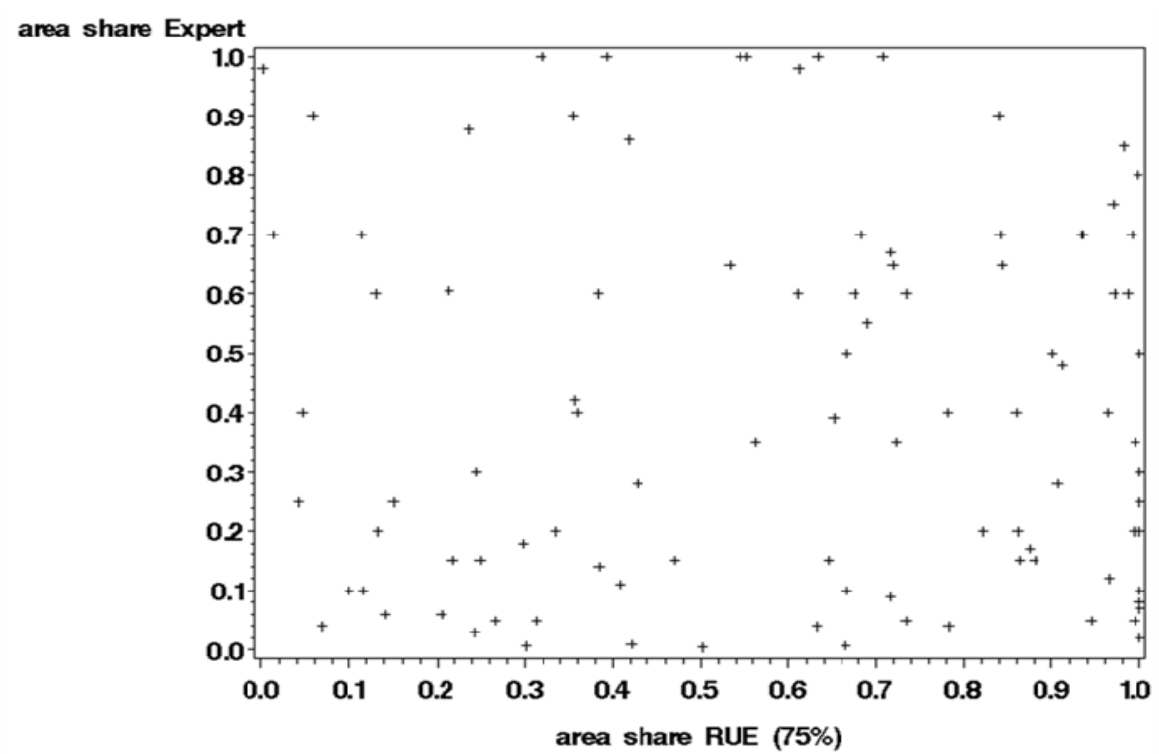

Figure 5. Area shares [0-1] of degraded land by production system zone for RUE trends with slope parameters at 75 percent confidence level and expert assessment

In a next step we use colors and symbols to identify patterns for the individual production systems zones. We plot area shares of RUE trend analysis and expert assessments, for rainfed, transhumant, forestry and nature reserve in Figure 6 with confidence levels of 90 percent (a) and 75 percent (b). Figure 7 (a and b) plots this information for production systems: peri-urban, irrigated, floodplains, agro-pastoral.

We observe for rainfed, agro-pastoral, flood plain and nature reserve a slight tendency that higher area shares of experts correspond to higher assessments of the RUE trend analysis, especially for data at the 90 percent confidence interval. However, the earlier observed bias is also found for these production systems as experts assessments are higher at the 90 percent confidence level and lower for the 75 percent level, compared to the RUE trend data. At both confidence intervals the relation for transhumant, forestry and irrigated areas is not very clear while degraded area shares for peri-urban areas are consistently lower for expert assessments as compared to the RUE trend analysis. 
We conclude that the selected data set at the 90 percent confidence interval are somewhat better interpretable. Therefore, we use these data to continue our comparison between RUE slope values and expert assessments on degree and rate of land degradation.
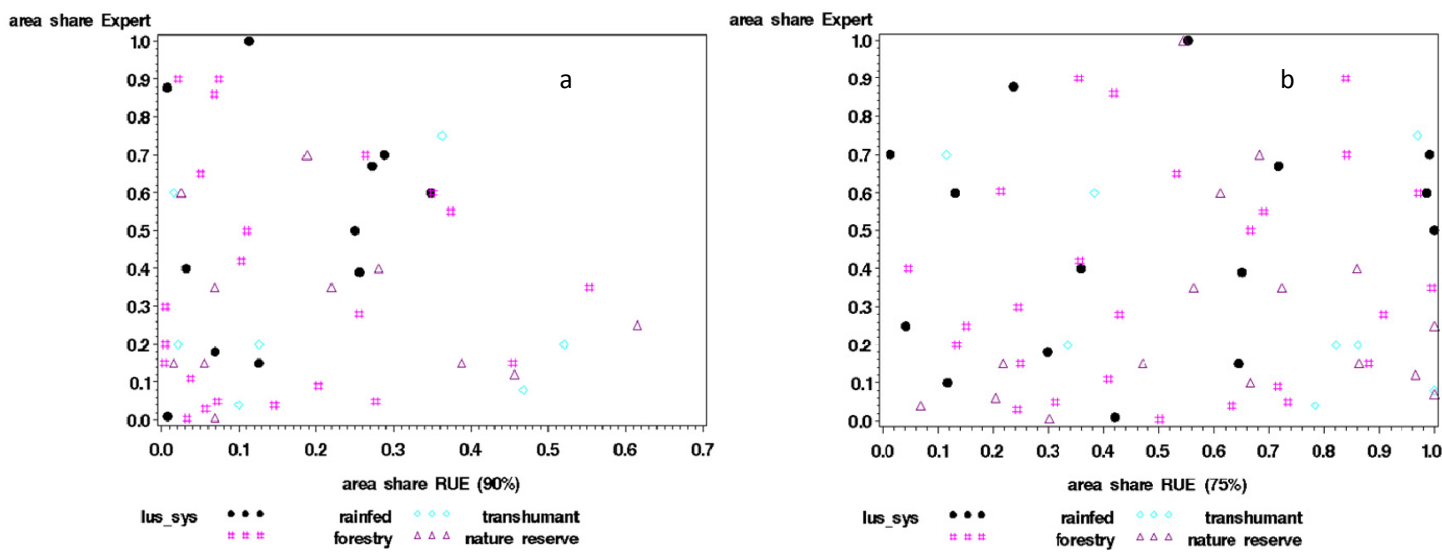

Figure 6. Area shares [0-1] of degraded land for RUE trends with confidence levels of 90 (a) and 75 percent (b) against expert assessment for production systems: rainfed, transhumant, forestry and nature reserve
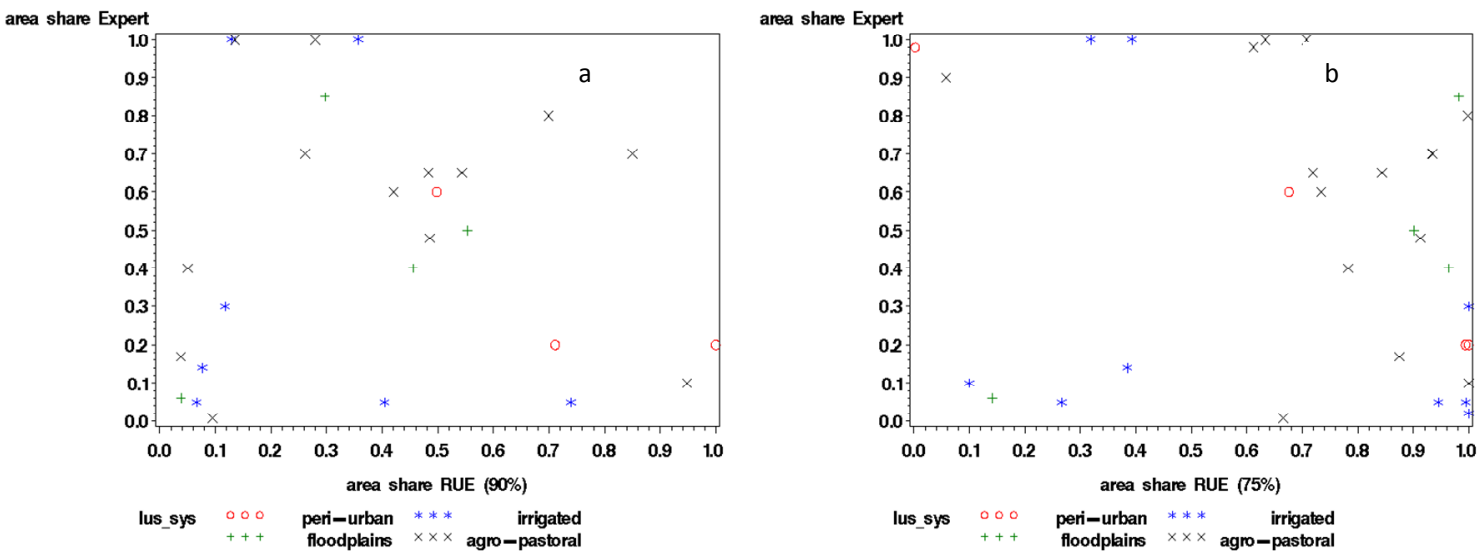

Figure 7. Area shares [0-1] of degraded land for RUE trends with confidence levels of 90 (a) and 75 percent (b) against expert assessment for production systems: peri-urban, irrigated, floodplains and agro-pastoral

\subsection{Comparing Degree of Degraded Land}

This section compares the degree of land degradation given by expert assessments against the value of RUE slope parameters. We, thereby, assume that lower (more negative) RUE slope values correspond to increasing degree of land degradation as indicated by experts. We start with an exploratory analysis using scatter plots of the RUE slope parameters (90 percent confidence level) against expert judgments on the degree of land degradation by production system zone (Figure 8 ). 

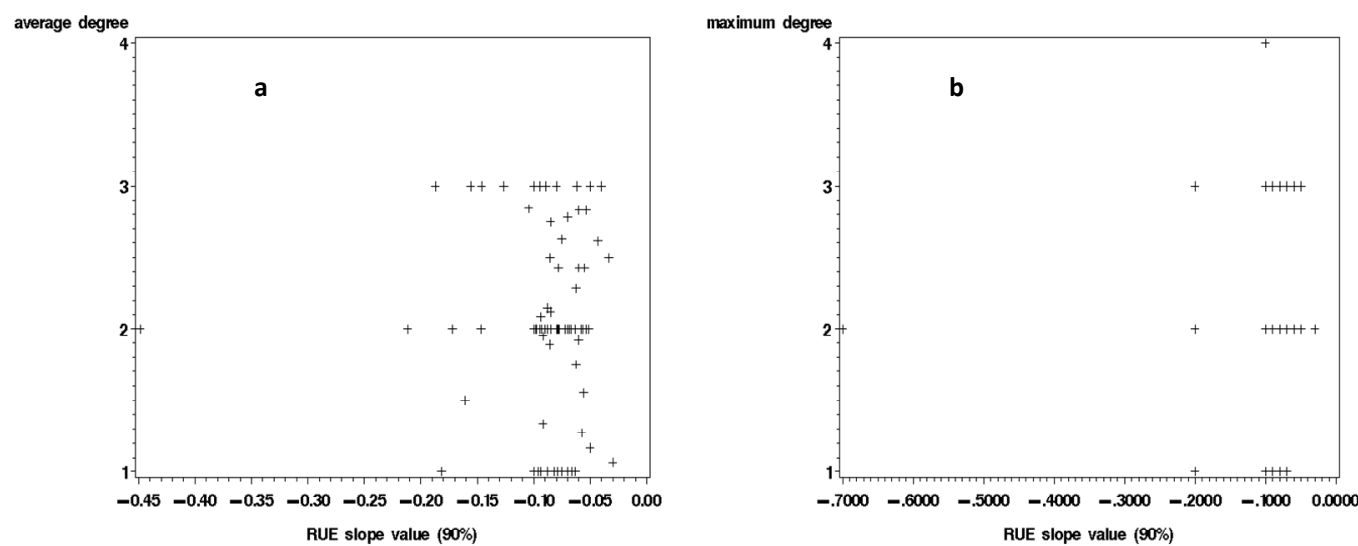

Figure 8. RUE slope values (90 percent confidence level) against expert judgments on the degree of land degradation by production system zone: a) average RUE slope values against the average weighted degree of land degradation; b) maximum RUE slope value against the maximum degree of land degradation

Figure $8 \mathrm{a}$ plots the average degree of land degradation expressed as its class number (numeric code) weighted by area share (e.g. Leiwen et al., 2005; Pace et al., 2008) against the average RUE slope value for the corresponding production system zone by district. It shows that most observations in the degree of land degradation that vary from class 1 to 3 ('Light' to 'Severe') are found in a narrow range of -0.10 to -0.05 RUE slope values. Class value 2 ('Moderate') and 3 ('Severe') corresponds to a wider range of RUE slope values as compared to class 1 ('Light'). Figure $8 \mathrm{~b}$ shows the maximum reported degree of land degradation against minimum RUE slope values. There is a high variation of RUE slope values by degree of land degradation, yet, we observe a slight tendency whereby higher degrees of land degradation correspond to lower RUE slope values. We repeated this exercise with RUE slope values that were significant at the 75 percent level and for all negative slope values. Yet, these patterns were less interpretable compared to the RUE slope values with a 90 percent confidence interval and will not be discussed further in this study.

As it is difficult to recognize certain configurations in the scatter plots of Figure 8 we continue with a smoothing technique that interpolate point observations and might reveal prevalent patterns more explicitly. The smoothing is done by the mollifier mapping, a flexible form of curve-fitting that follows the data closely and compensates for the lack of a priori knowledge of an explicit parametric functional form (Keyzer \& Sonneveld, 1998). The mollifier program implements a kernel density regression to show estimated values in 3-D graphs in a surface plot against two independent variables. Furthermore, the program generates statistics on reliability of the estimate and depicts these as color shifts in, respectively, the surface plot and ground plane. We used these statistics to zoom in on the reliable areas of the data domains.

Figure 9 shows the mollifier picture. The vertical $\mathrm{Y}$-axis depicts average RUE slope values, the SW-NE X-axis indicates the degree of land degradation, whereas the share of affected land of the production system is shown along the SE-NW axis. The surface plane shows the relation between RUE slope values, the degree of land degradation and the area share of land degradation. The color shift in surface and ground plane reflects the likelihood ratio of the estimated values, the distribution of which is shown in the legend.

The curve is more or less flat except for higher area shares affected by degradation and higher degrees of land degradation that correspond to the lowest RUE slope values, as expected. The relationship between the increasing degree of degradation and RUE is less clear. An increase in RUE values is observed for lower degrees and highest area shares of land degradation, yet, the lighter colours of likelihood statistics indicate that the data density is low and estimates are less reliable. 


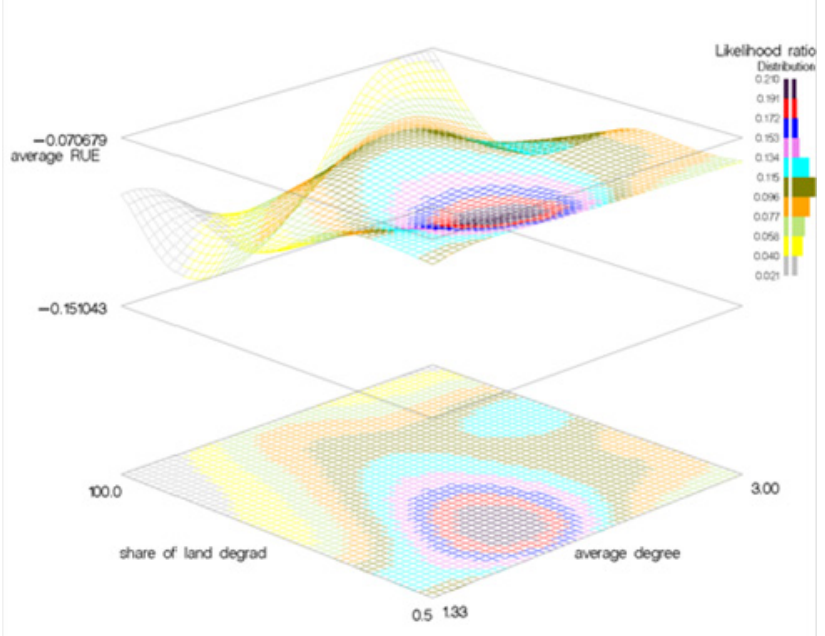

Figure 9. Average RUE slope values (y-axis) against the average degree of land degradation (SW-NE x-axis) and share (in \%) of affected areas (SE-NW x-axis); likelihood ratio depicted in planes with bar chart representing its frequency distribution

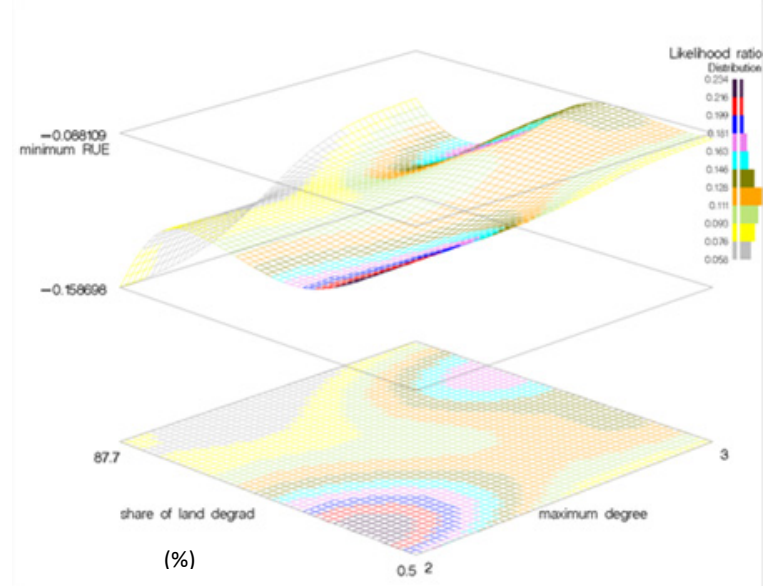

Figure 10. Minimum RUE slope values (y-axis) against maximum degree of land degradation (SE-NW x-axis) and share (in \%) of affected areas (SW-NE x-axis); likelihood ratio depicted in planes with bar chart representing its frequency distribution

We repeat the exercise for the extreme minimum RUE values and maximum degrees of land degradation. Figure 10 shows that lower values of area share and lower degrees of land degradation correspond to higher RUE values. The 'blanket' also declines, nicely, relating increasingly affected area shares with lower RUE values. The relationship for higher degrees of land degradation is less clear, especially for lower area shares, yet, it depicts, as expected, the lowest RUE values for higher degrees of land degradation and highest affected area shares.

\subsection{Comparing Rate of Degraded Land}

Rate. An evaluation of the rate of land degradation by experts, indicating the trend over the past 10 years, shows that 26 percent of the area has an increasing trend of land degradation, about five percent shows a decreasing trend while 2 percent remains stable. Figure 11 shows these trends of land degradation as a share of total area. The increasing trend is alarming as it might increase the degree and area share of land degradation. 


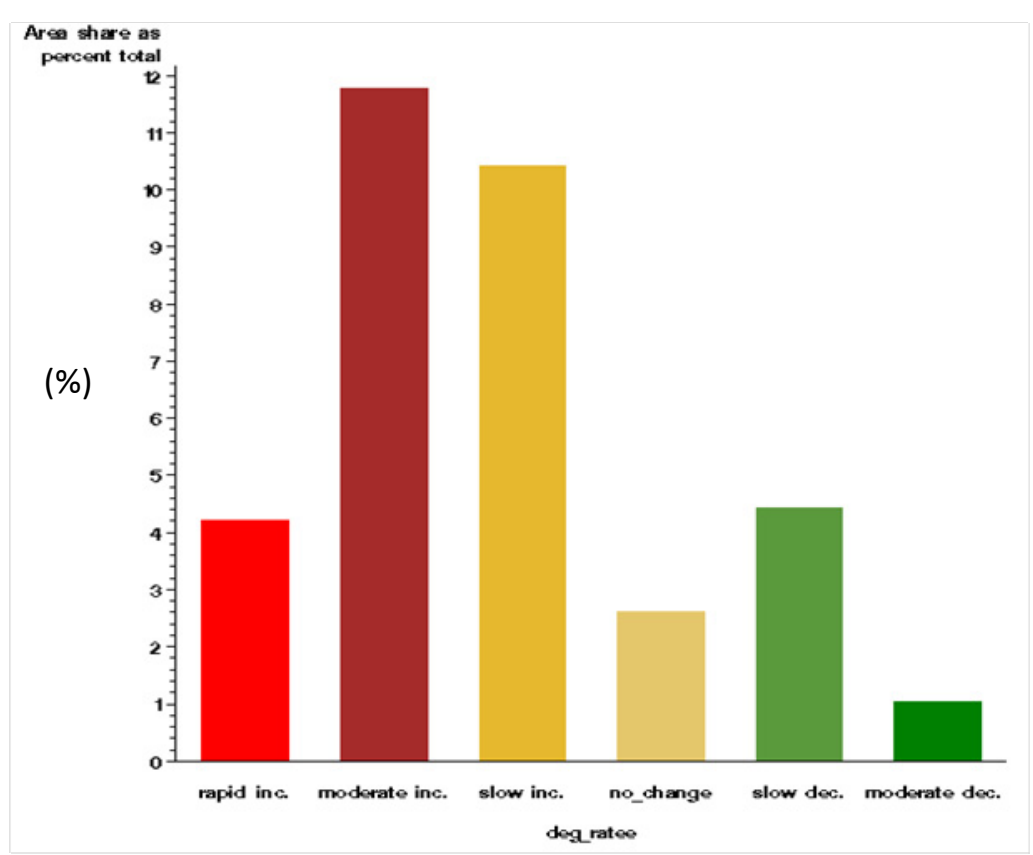

Figure 11. Degraded land as share (in \%) of total area by rate of land degradation; national level

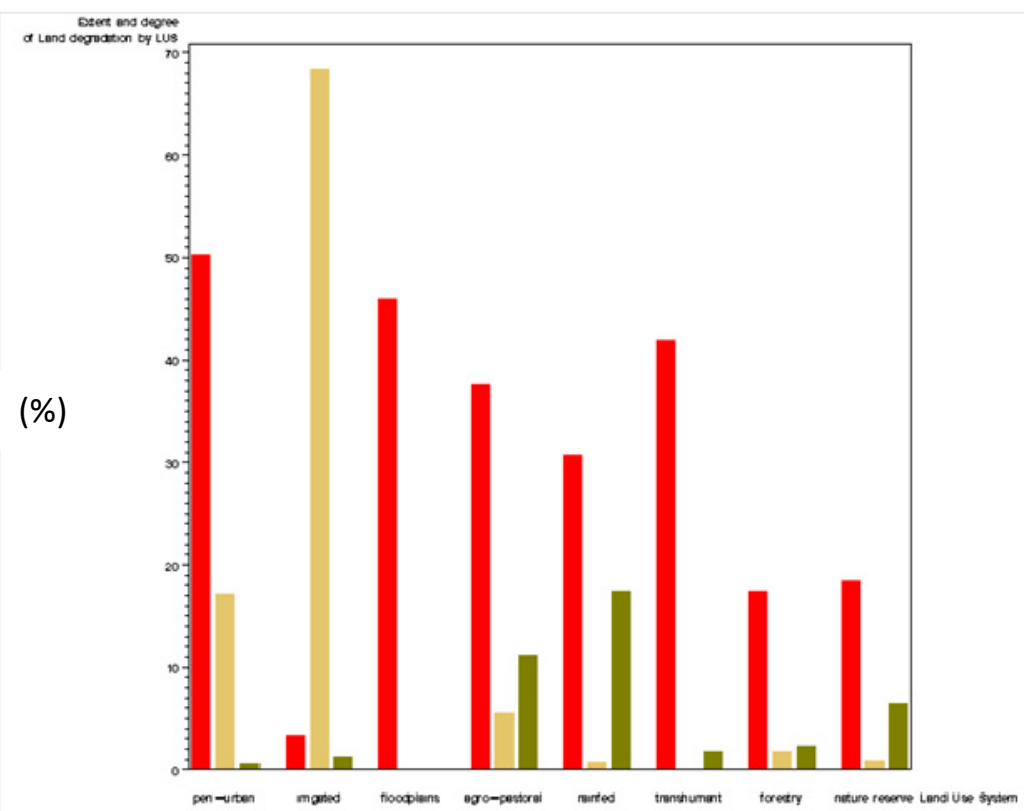

Figure 12. Area share (in \%) for the rate of land degradation by production system: red = increase; sandy brown $=$ stable; green $=$ decrease

Figure 12 shows the rate of land degradation per production system zone. Disturbingly, most production systems report a dominance of increasing rates of land degradation. Specifically, 'Peri-urban' (50 percent), 'Floodplain' (46 percent), 'Transhumant' (40 percent), 'Rainfed' (31 percent) and 'Agro-pastoral' (30 percent) show high shares of increasingly affected areas. Only 'Irrigated' areas seem to be stable, yet, these areas are already largely affected (Sonneveld et al., 2010). Obviously, land degradation is expected to increase rapidly in the coming years.

Figure 13 shows scatter plots of RUE slope estimates ( 90 percent confidence interval) against expert judgments for the rate of land degradation per production system and by district. Figure 13a shows the average rate of land degradation weighted by area share and average RUE slope values. We observe a slightly unexpected pattern in 
which higher expert rates on land degradation correspond to higher RUE slope values. Figure 13b plots maximum reported rates of land degradation against minimum RUE slope values. Also here we find a counterintuitive pattern where higher rates correspond with higher RUE slope values.

We repeated this exercise with RUE slope values that were significant at the 75 percent level and for all negative slope values. Yet, also here we did not find any patterns that gave an expected correlation and we will not discuss these findings here in further detail.

We conclude that the expected relationships between RUE slope value estimates and expert judgments on the rate of land degradation show counterintuitive results from what we expected.
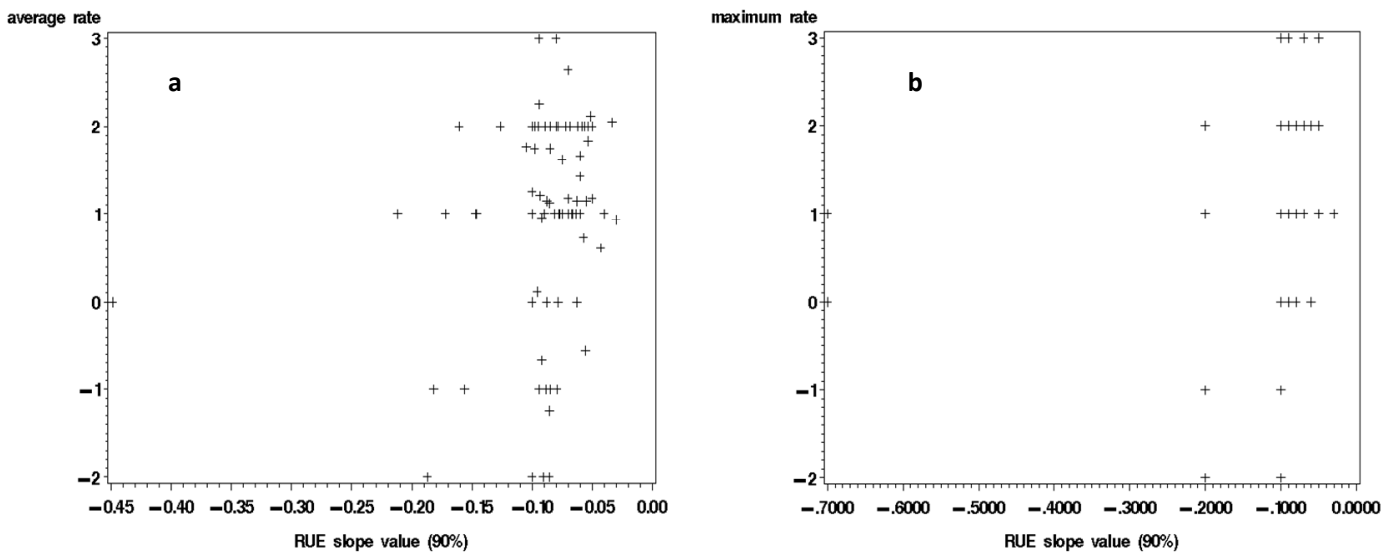

Figure 13. RUE slope values (90 percent confidence level) against expert judgments on the rate of land degradation by production system zone: a) the average RUE slope values against the average weighted degree of land degradation; b) minimum RUE slope value against maximum degree of land degradation

\section{Conclusion}

In this study we compared expert assessments on the degree, rate and area shares of land degradation with the results of a RUE trend analysis. We started with an evaluation of the consistency of expert assessments by comparing judgments on degree of land degradation for similar combinations of biophysical conditions and land use. Experts show a high consistency in their judgment on land degradation and are considered a reliable source for further analysis. We continued by comparing results of RUE trend analysis with the expert findings. We found that the correlation between experts and RUE assessment for area shares by district and production system zone is low. Zooming in on production system zones shows some improvement for rainfed, agro-pastoral, flood plain and nature reserve, yet, overall results are far from concise. Comparison between RUE slope values and degree of land degradation gave only interpretable results for extreme minimum RUE values and maximum degrees of land degradation. The relation between average RUE slope values and rate of land degradation provided counterintuitive outcomes.

Concerning the question whether experts or results of the RUE trend analysis are correct we like to note the following. The findings in section 3.1 showed that experts were consistent in their assessments and, consequently, we consider their registered area shares and degree of land degradation as objective measurement and not as subjective interpretations. Furthermore, we discussed in section 2 the several methodological shortcoming of the RUE trend analysis. Hence, to answer the earlier posed question, based on our empirical findings on consistency of expert judgments, the critics on RUE analysis and large deviations between RUE results and expert judgments, we consider expert opinions as the preferable option for a nation-wide land degradation assessment in Senegal.

Yet, this does not exempt expert approaches from the criticism and disputes earlier mentioned. On the contrary, we strongly advocate that the expert approach increases its analytical capacity and policy relevance by adopting the following adjustments. First, its explanatory power should be improved by expanding the independent variables that define the uniform map units, for which experts give their judgment (Note 4). Notably, the approach should expand on collecting information of the historical and institutional setting that proofs to be of imminent importance in the causal explanation of land degradation (e.g. Bouma, 2006). Concerning the crossing of the numerous variables, this amounts to an optimal stratification of the geography that minimizes variance of 
independent variables, thereby improving the preciseness of the expert judgments to explain land degradation incidence in its spatial dependence of biophysical and socio-economic variables. The finer resolution of map units also provides judicious interventions to address the location specific conditions. Clearly, including more factors introduces a curse of dimensionality as the combinatorics of several variables categorized in three or more classes easily explodes to thousands of possible combinations. This amounts to a trade-off between accuracy and (nation-wide) coverage of expert judgments. However, a sample of expert observations on selected map units can be used to estimate a qualitative response model (e.g. ordered logit model) whereby explanatory variables used in the crossing exercise reproduce ordered classes of expert opinions for unvisited sites (Sonneveld, 2003). Second, the use of a modelling framework that reproduces expert judgments also paves the way to simulate prospective scenarios under various land uses, and if information is available, with various land conservation techniques. This is a remarkable improvement with respect to the static expert judgment which can merely be depicted on a map but is inappropriate for the evaluation of policy interventions. Third, a quantitative interpretation of these qualitative judgments can be obtained by relating ordered classes to measured observations on land degradation (e.g. soil loss); this relationship will define the qualitative class boundaries in the dimensions of the dependent variable (Sonneveld \& Dent, 2007) providing quantitative interpretations to the qualitative classes.

\section{Acknowledgements}

This research was sponsored by the FAO-GEF-UNEP Land Degradation in Dryland Areas (LADA) project. The authors like to thank FAO counterparts F. Nachtergaele, R. Biancalani and S. Bunning and M Nubé of the Centre for World Food Studies for their comments on an earlier draft.

\section{References}

Aitkenhead, M. J., \& Aalders, I. H. (2011). Automating land cover mapping of Scotland using expert system and knowledge integration methods. Remote Sensing of Environment, 115, 1285-1295.

Bai, Z. G., van Lynden, G. W. J., Sahin, S., van Ierland, E., Cotteleer, G., \& Bindraban, P. S. (2011). Mapping Land Degradation and Risk in Turkey. ISRIC Report 2011/05. ISRIC, Wageningen, The Netherlands.

Bai, Z. G., Dent, D. L., Olsson, L., \& Schaepman, M. E. (2008). Global assessment of land degradation and improvement 1. Identification by remote sensing. LADA Technical Report \#12, FAO-ISRIC.

Bai, Z. G., \& Dent, D. L. (2007). Land degradation and improvement in Senegal. 1: Identification by remote sensing. Report 2007/07 (GLADA Report 1e), ISRIC - World Soil Information, Wageningen.

Beck, C., Grieser, J., \& Rudolf, B. (2005). A new monthly precipitation climatology for the global land areas for the period 1951 to 2000. Climate Status Report 2004. German Weather Service, Offenbach.

Beven, K. J. (1999). Calibration, Validation and Equifinality in Hydrological Modelling. In Anderson, M. G., \& Bates, P. D. (eds.), Model Validation in the Hydrological Sciences. Chichester: Wiley.

Bierens, H. J. (1987). Kernel density estimations of regression functions. Advances in Econometrics 6, Cambridge University Press.

Bindraban, P. S., Stoorvogel, J. J., Jansen, D. M., Vlaming, J., \& Groot, J. J. R. (2000). Land quality indicators for sustainable land management: proposed method for yield gap and soil nutrient balance. Agriculture, Ecosystems and the Environment, 81, 103-112.

Bindraban, P. S., (Jan) Verhagen, A., Uithol, P. W. J., \& Henstra, P. (1999). A land quality indicator for sustainable land management: the yield gap. Report no. 106. Research Institute for Agrobiology and Soil Fertility (AB-DLO).

Boer, M. M., \& Puigdefabregas, J. (2003). Predicting potential vegetation index values as a reference for the assessment and monitoring of dryland condition. International Journal of Remote Sensing, 24, 1135-1141.

Bouma, J. A. (2008). Voluntary cooperation in the provision of a semi-public good-Community-based soil and water conservation in semi-arid India. CentER Dissertation series 207, CentER graduate school, Tilburg University, Tilburg.

Desmet, P. J. J., Govers, G., Poesen, J., \& Goosens, D. (1995). GIS-based simulation of erosion and deposition patterns in an agricultural landscape: a comparison of model results with soil map information. In Poesen, J., \& Govers, G. (eds.), Experimental geomorphology and landscape ecosystem changes. Proceedings Memorial Symposium Prof. Jan De Ploey, Leuven, Belgium, 22-26 March, 1993. Catena, 25, 1-4, 389-401. 
Dianka, D. (2007). La migration internationale féminine individuelle à partir du Sénégal vers la France. Le cas des fatou-fatou. Thèse de Doctorat en Géographie Humaine, soutenue à l'université de Reims Champagne-Ardenne.

Diouf, A., \& Lambin, E. F. (2001). Monitoring land-cover changes in semi-arid regions: remote sensing data and field observations in the Ferlo, Senegal. Journal of Arid Environments, 48, 129-148.

Evans, J., \& Geerken, R. (2004). Discrimination between climate and human-induced dryland degradation. Journal of Arid Environments, 57, 535-554.

FAO. (2011). Manual for Local Level Assessment of Land Degradation and Sustainable Land Management. Part 1 - Planning and methodological approach, analysis and reporting. Land Degradation Assessment in Drylands Project. Food and Agriculture Organization of the United Nations, Rome, Italy.

Fensholt, R., \& Rasmussen, K. (2011). Analysis of trends in the Sahelian 'rain-use efficiency' using GIMMS NDVI, RFE and GPCP rainfall data. Remote Sensing of Environment, 115, 438-451.

Gachene, C. K. K. (1995). Evaluation and mapping of soil erosion susceptibility: an example from Kenya. Soil Use and Management, 11(1), 1-4.

Geerken, R., \& Ilaiwi, M. (2004). Assessment of rangeland degradation and development of a strategy for rehabilitation. Remote Sensing of Environment, 90, 490-504.

Hall, F., Masek, J., \& Collatz, G. J. (2006). Evaluation of ISLSCP Initiative II FASIR and GOMMS NDVI products and implications for carbon cycle science. Journal of Geophysical Research, 111. D22S08 http://dx.doi.org/10.1029/2006JD007438

Hill, M. J., Lesslie, R., Donohue, R., Houlder, P., Holloway, J., Smith, J., \& Ritman, K. (2006). Multi-Criteria Assessment of Tensions in Resource Use at Continental Scale: A Proof of Concept with Australian Rangelands. Journal Environmental Management, 37(5), 712-731.

Houérou, H., \& Le, N. (1984). Rain-use efficiency: a unifying concept in arid-land ecology. Journal of Arid Environments, 7, 213-247.

Huenneke, L. F., Anderson, J. P., Remmenga, M., \& Schlesinger, W. (2002). Desertification alters patterns of above ground net primary production in Chihuahuan ecosystems. Global Change Biology, 8, 247-264.

Jager, S. (1994). Modelling regional soil erosion susceptibility using the Universal Soil Loss Equation and GIS. In Rickson, R. J. (ed.), Conserving soil resources: European perspectives (pp. 161-177). CAB International, Wallingford, UK.

Kairé, M. (2003). Etude de la biodiversité agroforestière dans les agrosystèmes du Bassin Arachidier du Sénégal. Rapport ISRA (p. 9).

Kelly, V., Diagana, B., Reardon, T., Gaye, M., \& Crawford, E. (1996). Cash crop and foodgrain productivity in Senegal: historical view, new survey evidence, and policy implications. International Development Paper, No. 20, Michigan State University, East Lansing, MI.

Keyzer, M. A., \& Sonneveld, B. G. J. S. (1998). Using the mollifier method to characterize datasets and models: the case of the Universal Soil Loss Equation. ITC Journal, 3-4, 263-272.

Lal, R. (2011). Soil Degradation and Food Security in South Asia. In Lal, R. et al. (eds.), Climate Change and Food Security in South Asia, 138-152. http://dx.doi.org/10.1007/978-90-481-9516-9_10

Leeuw, P. N. DE, \& Milligam, K. (1984). A review of integrated surveys for resource inventory and monitoring of pastoral production systems in sub-Saharan Africa. ILCA BULLETIN. No. 20. Retrieved from www.ilri.org

Leiwen, J., Yufen, T., Zhijie, Z., Tianhong, L., \& Liao, J. (2005). Water Resources, Land Exploration and Population Dynamics in Arid Areas - The Case of the Tarim River Basin in Xinjiang of China. Population \& Environment, 26(6), 471-503.

Li, J., Lewis, J., Rowland, J., Tappan, G., \& Tieszen, L. L. (2004). Evaluation of land performance in Senegal using multi-temporal NDVI and rainfall series. Journal of Arid Environments, 59, 463-480.

Liniger, H. G., van Lynden, Nachtergaele, F., \& Schwilch, G. (2008). Questionnaire for Mapping Land Degradation and Sustainable Land Management. CDE/WOCAT, FAO/LADA, ISRIC, WOCAT Secretariat. Bern, Switzerland. 
Liu Y., Gao, J., \& Yang, Y. (2003). A Holistic Approach Towards Assessment of Severity of Land Degradation Along the Great Wall in Northern Shaanxi Province, China. Environmental Monitoring and Assessment, 82(2), 187-202.

Mbow, C., Mertz, O., Diouf, A., Rasmussen, K., \& Reenberg, A. (2008). The history of environmental change and adaptation in eastern Saloum-Senegal-Driving forces and perceptions. Global and Planetary Change, 64, 210-221.

McDowell, R. E., \& DeHaan, C. (1986). West African Agricultural Research Review: Livestock Research.

McNaughton, S. J., Oesterheld, M., Frank, D. A., \& Williams, K. J. (1989). Ecosystem-level patterns of primary productivity and herbivory in terrestrial habitats. Nature, 341, 142-144.

Mitas, L., \& Mitasova, H. (1998). Distributed soil erosion simulation for effective erosion prevention. Water Resources Research, 34(3), 505-516.

Mitasova, H., Hofierka, J., Zlocha, M., \& Iverson, L. R. (1997). Reply to comment by Desmet \& Govers. International Journal of Geographical Information Systems, 11(6), 611-617.

Mortimore, M., Ba, M., Mahamane, A., Rostom, R. S., Serra Del Pozo, P., \& Turner, B. (2005). Changing systems and changing landscapes: measuring and interpreting land use transformations in African drylands. Geografisk Tidsskrift. Danish Journal of Geography, 105, 101-120.

Mulitza, S., Heslop, D., Pittauerova, D., Fischer, H. W., Meyer, I., Stuut, J., ... Schulz, M. (2010). Increase in African dust flux at the onset of commercial agriculture in the Sahel region. Nature, 466, 226-228.

Oldeman, L. R., Hakkeling, R. T. A., \& Sombroek, W. G. (1991). World map of the status of human induced soil degradation. ISRIC/UNEP. Wageningen.

Niemeijer, D., \& Mazzucato, V. (2002). Discrepancies about soil degradation. Environment, 44(7), 40-42.

Pace, G., Vaglio, G., Laurin, L., Pires, D. R., \& Sciortino, M. (2008). Space For The Unced And The Desertwatch Project. Alberto Marini \& Mohamed Talbi. Desertification and Risk Analysis Using High and Medium Resolution Satellite Data. NATO Science for Peace and Security Series C: Environmental Security. pp 71-82.

Pla Sentis, I. (1997). A soil water balance model for monitoring soil erosion processes and effects on steep lands in the tropics. Soil Technology, 11(1), 17-30.

Prince, S. D., Brown de Colstoun, E., \& Kravitz, L. L. (1998). Evidence from rain-use efficiencies does not indicate extensive Sahelian desertification. Global Change Biology, 4, 359-374.

Reardon, T., Kelly, V., Crawford, E., Diagana, B., Dione, J., Savadogo, K., \& Boughton, D. (1997). Promoting sustainable intensification and productivity growth in Sahel agriculture after macroeconomic policy reform. Food Policy, 22, 4, 317-327.

Reardon, T., Barrett, C. B., Kelly, V., \& Savadogo, K. (1998). Sustainable Versus Unsustainable Agricultural Intensification in Africa: Focus on Policy Reforms and Market Conditions. Paper invited for presentation at the AAEA International Preconference on "Agricultural Intensification, Economic Development and the Environment," July 31-August 1, 1998, Salt Lake City, Utah.

Requier-Desjardins, M., Adhikari, B., \& Sperlich, S. (2011). Some notes on the economic assessment of land degradation. Land Degradation and Development, 22, 285-298.

Rey, C., Scoones, I., \& Toulmin, C. (1998). Sustaining the soil: indigenous soil and water conservation in Africa (Chapter 1). In Rey, C., Scoones, I., \& Toulmin, C. (eds.), Sustaining the Soil (pp. 1-27). Indigenous SWC in Africa. Earthscan, London.

Reynolds, J. F., Stafford, \& Smith, D. M. (2002). Global Desertification: Do Humans Cause Deserts? 88. Berlin: Dahlem University Press.

Safriel, U. N. (2007). The assessment of global trends in land degradation. In Sivakumar, M. V. K., \& Ndiang'ui, N. (eds.), Climate and land degradation (pp. 2-38). New York: Springer.

Sonneveld, B. G. J. S. (2003). Formalizing the use of expert judgements for land degradation assessment: a case study for Ethiopia. Land Degradation and Development, 14, 347-361. http://dx.doi.org/10.1002/ldr.564

Sonneveld, B. G. J. S., \& Albersen, P. A. (1999). Water erosion assessment based on expert knowledge and limited information using an ordered logit model. Journal of Soil and water Conservation, 54(3), 592-597. 
Sonneveld, B. G. J. S., \& Dent, D. (2007). How good is GLASOD? Journal of Environmental Management. http://dx.doi.org/10.1016/ j.jenvman.2007.09.008

Sonneveld, B. G. J. S., Pande, S., Keyzer, M. A., Georgis, K., Seid Ali, A., \& Takele, A. (2010). Land degradation and overgrazing in the Afar Region, Ethiopia: a spatial analysis using Rainfall Use Efficiency. In Zdruli, P., Pagliai, M., Kapur, S., \& Faz Cano, A. (eds.), Land Degradation and Desertification: Assessment, Mitigation and Remediation (pp. 97-110). Germany: Springer.

Sonneveld, B. G. J. S., Keyzer, M. A., Zikhali, P., \& Merbis, M. D. (2010). National Land Degradation Assessment Senegal and Review of global socio-economic parameters in the LADA data base. Land Degradation Assessment (LADA) project. SOW-VU, Amsterdam. Report for the Food and Agricultural Organization of the United Nations, Rome.

Sonneveld, B. G. J. S., Keyzer, M. A., Zikhali, P., \& Merbis, M. (2011). Local land degradation assessment, soil conservation and nutrient balances in Senegal. Land Degradation Assessment (LADA) project. SOW-VU, Amsterdam. Report for the Food and Agricultural Organization of the United Nations, Rome.

Speirs, M., \& Olson, O. (1992). Indigenous integrated farming systems in the Sahel. World Bank Technical Paper No. 179, African Technical Department Series, World Bank, Washington, DC.

Symeonakis, E., \& Drake, N. (2004). Monitoring desertification and land degradation over sub-Saharan Africa. International Journal of Remote Sensing, 25(3), 573 - 592.

Tschakert, P., \& Tappan, G. (2004). The social context of carbon sequestration: considerations from a multi-scale environmental history of the Old Peanut Basin of Senegal. Journal of Arid Environments, 59, 535-564.

Tucker, C. J., Pinzon, J. E., \& Brown, M. E. (2004). Global inventory modeling and mapping studies (GIMMS) satellite drift corrected and NOAA-16 incorporated normalized difference vegetation index (NDVI), monthly 1981-2002. University of Maryland.

UN. (1994). UN Earth Summit. Convention on Desertification. UN Conference in Environmentand Development, Rio de Janeiro, Brazil, June 3-14, 1992. DPI/SD/1576. United Nations, New York.

Veron, S. R., Paruelo, J. M., \& Oesterheld, M. (2006). Assessing desertification. Journal of Arid Environments, 66, 751-763.

Vincke, C., Die'dhiou, I., \& Grouzis, M. (2009). Long term dynamics and structure of woody vegetation in the Ferlo (Senegal), Journal of Arid Environments. http://dx.doi.org/10.1016/j.jaridenv.2009.08.006

Wessels, K. J. (2009). Comments on 'Proxy global assessment of land degradation' by Bai et al. (2008). Letter to the Editor. Soil Use and Management, 25, 91-92

Wischmeier, W. H. (1976). Use and misuse of the universal soil loss equation. Journal of Soil and Water Conservation, 31, 5-9.

Wood, E. (2002). Modeling and characterizing agricultural expansion: a case study in Senegal. Ph.D. Dissertation, University of Wisconsin, Madison.

Wood, E. C., Tappan, G. G., \& Hadj, A. (2004). Understanding the drivers of agricultural land use change in south-central Senegal. Journal of Arid Environments, 59, 565-582.

Yu, B., Rose, C. W., Yin, D., \& Anecksamphat, C. (2001). Re-interpretation of USLE Datasets for Physically Based Erosion Models with Examples From Southern China and Northern Thailand. In Stott, D. E., Mohtar, R. H., \& Steinhardt, G. C. (Eds.). Sustaining the Global Farm - Selected papers from the $10^{\text {th }}$ International Soil Conservation Organization Meeting, May 24-29, 1999, West Lafayette, IN., pp. 929-934.

Zeleke, G. (2000). Landscape Dynamics and Soil Erosion Process Modelling in the North-western Ethiopian Highlands. Ph.D. Thesis. Centre for Development and Environment. Bern University.

\section{Notes}

Note 1. To compare grazing demand or environmental pressure of different species in common units, animals body weights were converted into TLU equivalents.

Note 2. Number of persons living in areas $>9000$ persons per sq km (30 149 200) is close to the non-agricultural population estimated by FAOSTAT (accessed October 2009) (3 170 000). A closer look at the map showed that 
the threshold of 9000 persons per sq km coincides with the largest cities (e.g. Gran Dakar, Thies, Diourbel, Sant Louis, Kaolack, Tambacounda and Ziguinchor).

Note 3. Total area refers to 96 percent of the land area for which a degradation assessment was made. Marginal areas (4 percent) were not included in these assessments.

Note 4. Map units in Senegal, based on a crossing of districts and production systems, leaves other explanatory variables (e.g. soils, climate, distance markets) with a large variation that confuses explanation of land degradation incidences. 